\title{
The Asean Socio-Cultural
}

\section{Community ASCC for the Office of The Higher Education for The Asean Fine Arts Symposium (AFAS) 2015}

\section{Fortunata Tyasrinestu}

AFAS 2015 was held on May 23, 2015 at Grand Millennium Sukhumvit Bangkok Thailand.

This is the third annual event held in Bangkok, as one of the rapid developing cities with a dynamic economy and a progressive society in Southeast Asia. The city is developing into a regional center that can be a contender to Singapore and Hong Kong. Varied with cultural sites make Bangkok as one of the most popular tourist destinations in the world. Bangkok province is bordered by six other provinces: Nonthaburi, Pathum Thani, Samut Sakhon and Nakhon Pathom. While Sukhumvit is a special district in Bangkok. While Sukhumvit is an exclusive district in Bangkok. It is home to fancy apartments, villas, restaurants, bars and clubs. Popular among foreign visitors and expats, it becomes more and more a Thai residential neighbourhood as you follow the road southeast.

The Asean Socio-Cultural Community (ASCC) reflects ASEAN's social agenda that is focuses on poverty eradication and human development. It is linked inextricably with the economic and security pilars of the ASEAN Community. Social inequities can threaten economic development and in turn undermine political regimes. Economic instability can exacerbate poverty, unemployment, hunger, illness and disease. Social instability can emerge from environmental scarcity or the inequitable distribution among stakeholders of the use of enviromental assets. Failure to address these critical and persistent social issues can further cause both economic and political dislocation (Association of South East Asian Nation, 2015).

Implementing the ASCC PoA will require intensive and sustained capacity building at the national and regional levels in a wide range areas. Active participation of various stakeholders in ASCC activities will also be encouraged 
to draw from their wealth of expertise and experience and to promote a strong sense of commitment and ownership of project and activities. Building regionwide networks of NGOs, training centres, academic institutions and other ASEAN organisations will gradually weave into the fabric of the ASEAN Community and help to strengthen social cohesion.

As stated by Assoc Prof. Sineenart Laedpriwan, who is the editor in chief, "The Faculty of Fine Arts at Srinakharinwirot University which has been established for 20 years and offer Fine Arts degree from BA, MFA leading to the DA, with its goal to provide Fine Arts educations, researches and services will host ASEAN Fine Arts Symposium on Fine Arts in association with Arts and Applied Arts institution from all parts of the world especially ASEAN to provide Association of Southeast Asian Nations (ASEAN) the concept of "One vision, one identity, one community"

The primary goal of ASCC is to contribute to realizingan ASEAN Community that is people-centred and socially responsible with a view to achieving enduring solidarity and unity among the nations and peoples of ASEAN by forging a common identity and building a caring and sharing society which is inclusive and harmonious where the well-being, livelihood, and welfare of the peoples are enhanced.

The ASCC will address the region's aspiration to lift the quality of life of its peoples through cooperative activities that are people-oriented and environmentally friendly geared towards the promotion of sustainable development.

According to the 3rd ASEAN Fine Arts Symposium (AFAS) 2015 held by the university network from the collaborate academy such the Indonesian Institute of the Arts- Indonesia, University of Philippines, Mirium College Philippines, University of Malaya. Birmingham City University, Illinois State University and Srinakharinwirot University.

The research papers are presented under the theme ASEAN Socio-Cultural Community Moving Forward by means of the region's aspiration to lift the quality of life of its people through cooperative activities that are people-oriented and environmentally friendly geared towards the promotion of sustainable development. The ASCC shall contribute to building a strong fondation for greater understanding, good neighborliness and a shared senses of responsibility.

The secretary of the office of the higher education Associate Professor Dr. Pinniti Rattananukoon says that there are full of social and economic ideas to develop the country in between ASEAN to be much more strength in the area of Fine Arts. "However, we are such a country deeply in culture which has plenty of local wisdom. Therefore, I would believe that if all those wisdom could increase the special identity brand for ASEAN product such as music instrument, painting, sculpture, or even product of arts. In the meantime, the education should be 
developed and concerned more in the research for socio-cultural community. There are so many parts of each country intellectual property and local wisdom wich are so delightful.

The goal of this conference is to bring together researchers from academia and practitioners to share ideas, problems, and solutions. The conference have 26 research papaers separated to be six oral and 14 poster presentation. All research papers from delegate academic institution. The research papers are all in the proceeding report. Each session consists of between 6 to 15 people with 4 reviewers. Its implementation was technically made with oral presentation system consisting of three or four speakers. The presentations of the symposium was divided into 3 session. Session 1 for ethnomusicology, asian music arts education, session 2 for visual arts and design, and session 3 for performing arts. Each speaker was given the opportunity to present his papaer for 15-20 minutes, followed by a question and answer of the reviewer and the inter speaker and audiences.

These full papers were peer reviewed from the editorial board from four institution: the Indonesian Institution of the Arts, University of Philippines, University of Malaya, Mirium College and Srinakharinwirot University. Including professors from the university in Thailand such as Chulalongkorn University, Kasetsart University, Bangkok University, etc.

In the meantime, the education should be developed and concerned more in the research for socio cultural community. There are so many parts of each country intellectual property and local wisdom which are so delightful. All research papers should be worth for public and created the new knowledge to the world. 